\title{
LEITURAS DAS RELAÇÕES PORTUGAL-BRASIL NAS REVISTAS A ÁGUIA E NAÇÃO PORTUGUESA, 1910-1926
}

Luciana Lilian de Miranda ${ }^{1}$

RESUMO: Nesse trabalho, buscamos problematizar as leituras nas páginas de duas importantes revistas portuguesas; A Águia (1910-1932) e a Nação Portuguesa (1914-1938), acerca da relação entre Portugal e Brasil, nos anos da I República Portuguesa. Os dois periódicos em questão apresentaram diferentes matrizes teóricas e posicionamentos políticos, os quais buscamos situar com o intuito de uma melhor compreensão dos olhares sobre os vínculos histórico-culturais entre os dois países. A ênfase da nossa análise concentra-se nos debates e tensões entre os círculos de intelectuais nas duas margens do Atlântico, assim como, nas representações construídas por esses personagens acerca das relações luso-brasileiras.

PALAVRAS-CHAVE: Revistas. Intelectuais. Relações PortugalBrasil.

1 Bolsista de Estágio Pós-Doutoral (PNPD/Capes) do Programa de PósGraduação em História da UFG/Goiânia. Doutora em História Contemporânea pela Universidade Nova de Lisboa (UNL, 2014). Mestre em História Social pela Universidade Federal de Uberlândia (UFU, 2003). Bacharel e Licenciada pela mesma instituição (UFU, 2000). Foi docente do Curso de Graduação em História da Universidade Metodista de Piracicaba (UNIMEP, 2014-2015) e docente substituta do Instituto de História da UFU (Graduação, 2005-2006). Temáticas de interesse: História das relações culturais entre Brasil e Portugal (1900-1930), Primeiras Repúblicas Brasileira e Portuguesa, História dos Intelectuais, História e Literatura e História da Educação Luso-brasileira. Lattes: http://lattes.cnpq. br/0183619176915821. E-mail: ॥lm.miranda@gmail.com . 
ABSTRACT: In this paper, we discuss the views presented by two major Portuguese magazines; A Águia (1910-1932) and Nação Portuguesa (1914-1938), on the relationships between Portugal and Brazil in the years of the First Portuguese Republic. The two journals had different theoretical references and political positions, which we seek to explain to better understand the views of the historical and cultural ties between both countries. Our analysis focuses on the debates and tensions between the intellectual circles on both sides of the Atlantic as well as the representations built by these characters on the Luso-Brazilian relations.

KEYWORDS: Magazines. Intellectuals. Portugal-Brazil Relations.

\section{Considerações Iniciais}

Em linhas gerais, a virada do século XIX para o $X X$ foi marcada pelo processo de criação ou reestruturação dos Estados Nacionais. O fluxo intenso de mudanças estimulado pela nova dinâmica da economia capitalista global afetaria "desde a ordem e as hierarquias sociais até as noções de tempo e espaço das pessoas" (SEVCENKO, 2008, p. 7).

Tratou-se ainda de um processo de reconstrução históricosociológico e de reinvenção das tradições e identidades nacionais, que permeou os regimes republicanos instaurados no Brasil e em Portugal.

Algumas das interpretações produzidas nessa época sobre o passado e as então perspectivas presentes e futuras de cada país, ultrapassaram a condição de modelos discursivos e foram incorporadas por segmentos sociais. Melhor dizendo, deixaram as suas marcas, influenciando a maneira como os brasileiros e portugueses se auto identificam e representam.

No cenário brasileiro, o debate intelectual dividia-se entre as teses que apoiavam a continuidade da tradição cultural portuguesa, branca e europeia como plasmadora da identidade nacional e aquelas que defendiam uma ruptura com o passado 
colonial e imperial. Do lado português, as elaborações sobre o passado reforçavam a imagem de Portugal como o gerador de nações. Construíram-se visões de um passado representificado, com base na gesta dos descobrimentos. Essa lógica pautava-se numa noção de tempo não linear, na qual passado, presente e futuro são indissociáveis criando possibilidades de se dar futuro ao passado, representificando-o (PINHO; NATÁRIO, 2011, p. 16).

Ao propormos uma análise das relações luso-brasileiras nos periódicos A Águia e Nação Portuguesa, visamos desvelar a visão que se projetava de Portugal e do Brasil nesses periódicos com diferentes matrizes teóricas.

Cada uma dessas revistas representava uma corrente do pensamento filosófico-político e literário da época. Assim temos A Águia (1910-1932), como órgão da Renascença Portuguesa ou do Neo-romantismo saudosista e a Nação Portuguesa (1914-1938) como célula do Integralismo Lusitano ou Neo-romantismo Lusitanista. As vanguardas de intelectuais fundadores dessas publicações representavam grupos com importante papel no pensamento filosóficopolítico no cenário português da época.

Consideramos os intelectuais enquanto sujeitos pensantes e agentes de mediação cultural. Nesse sentido, compartilhamos da abordagem da história dos intelectuais, que se dedica a problematizar a sua historicidade e complexidade (GOMES; HANSEN, 2016, p. 10-12).

A mesma encontra-se associada ao desenvolvimento da história cultural e da nova história política, ambas reconhecidas internacionalmente nos finais do século XX. Portanto, nas décadas de 1980 e 1990, com as críticas aos modelos explicativos macrossociais e deterministas, abriram-se novos campos de análise, os quais possibilitaram o retorno dos sujeitos históricos à História, inclusive para a categoria dos intelectuais. A partir disso:

A figura do intelectual, como sujeito pensante e agente, ganha centralidade e concretude. Os intelectuais têm um processo de formação e aprendizado, sempre atuando em conexão com outros 
atores sociais e organizações, intelectuais ou não, e tendo intenções e projetos no entrelaçamento entre o cultural e o político [...] Não obstante, demonstra ser de grande proveito e potencial para a reflexão teórica enquanto categoria de análise, o que fica evidente pelos diversos autores que dele se aproximam a partir de variadas perspectivas. (GOMES; HANSEN, 2016, p. 12).

Nas partes seguintes do texto, dedicar-nos-emos à análise das diretrizes de pensamento e das representações acerca das relações luso-brasileiras divulgadas nas revistas em questão.

\section{A Águia e o intercâmbio cultural Portugal-Brasil}

A Águia2, "revista quinzenal ilustrada de literatura e crítica", teve início em dezembro de 1910 no Porto, pouco depois da proclamação da República. Iniciou-se com uma edição quinzenal e depois, numa segunda fase, tornou-se mensal. A partir de 1912, constitui-se como órgão do movimento sócio-cultural da Renascença Portuguesa, inaugurando-se a segunda série do periódico, cujo subtítulo passou a ser; "revista mensal de literatura, arte, ciência, filosofia e crítica social”.

Na sua primeira etapa, não foi uma revista de doutrinação e esteve sob a direção e propriedade do jornalista Álvaro Pinto. Entretanto, nesse período já contava com a colaboração de escritores, tais como: Teixeira de Pascoaes (1877-1952), Jaime Cortesão (18841960), Leornardo Coimbra (1883-1936), os quais iriam integrar a Renascença Portuguesa, dentre outros. É interessante ressaltar, que o escritor, poeta, pedagogo e político português João de Barros (1881-1960) ${ }^{3}$ colaborou nessa fase, sobretudo com poesias,

2 Disponível para consulta, em formato digital, na Biblioteca Nacional de Portugal (BNP): <http://purl.pt/12152>.

3 Colaborações de João de Barros na revista A Águia: Primavera (n. 3, p. 6, jan. 1911); Para o Mar (n. 9, p. 12, maio 1911); Manuel Laranjeira (n. 4, $2^{\text {a }}$ série, p. 128-129, abr. 1912); Os artistas e a Guerra (ns. 52/53/54, p. 138, abr., aio-jun. 1916). 
afastando-se depois do grupo e tornando-se um dos fundadores da Atlântida ${ }^{4}$ no final de 1915.

A Renascença Portuguesa foi um movimento cultural iniciado em 1912 no Porto, que se manteve ativo durante o primeiro quartel do século $\mathrm{XX}$. Tinha como base um ideal nacionalista vinculado, no plano literário e filosófico, ao neo-garrettismo e a um sebastianismo quase messiânico.

A crise do Ultimatum inglês de $1890^{5}$, produziu na literatura portuguesa a renovação de um sentimento patriótico de ressignificação dos valores míticos e nacionais. Buscava-se, por meio do sonho, alimentar a esperança duma possível renovação do país, ultrapassando-se o estigma da humilhação impingida pela Inglaterra.

A partir desse contexto, criou-se um largo movimento intelectual, denominado Neogarretismo. Tomando-se Almeida Garret como modelo, o movimento valorizava o regresso ao passado, a simplicidade da vida rural, o interesse pelo regionalismo, o culto das tradições, o folclore e a busca da pureza da linguagem (CAMEIRÃO, 2000, p. 21).

4 A Atlântida; mensário artístico literário e social para Portugal e Brasil, foi pensada com o propósito de suscitar um intercâmbio cultural entre os países. A revista nasceu da união entre João de Barros e o cronista carioca Paulo Barreto; o João do Rio. Os dois expoentes das letras tinham uma causa em comum: renovar e intensificar as relações luso-brasileiras. Editado em Lisboa, nos anos de 1915 a 1920, o mensário apresentou importante colaboração de escritores portugueses e brasileiros.

5 Trata-se do episódio do ultimato do então governo britânico entregue a 11 de janeiro de 1890, na forma de um memorando, que exigia de Portugal a retirada das forças militares do território compreendido entre as colônias de Moçambique e Angola (atuais Zimbabwe e Zâmbia). A região era reclamada por Portugal, que a havia incluído no famoso Mapa cor-de-rosa, reclamando a partir da Conferência de Berlim uma faixa de território que ia de Angola à Moçambique. A concessão de Portugal às exigências britânicas foi vista como uma humilhação nacional pelos republicanos portugueses, que acusaram o governo e o rei D. Carlos I pela responsabilidade do ocorrido. A esse respeito cf. TEIXEIRA (2013). 
O mito de D. Sebastião, também referência para o grupo da Renascença, remetia ao símbolo do redentorismo social e nacional. Durante os séculos XIX e início do XX, o sonho heroico de D. Sebastião, a sua morte na Batalha de Alcácer-Quibir, o mito do seu regresso e a quimera do Quinto Império ${ }^{6}$ serviram de inspiração aos escritores, como forma de superar as angústias e as incertezas da época. O mito apaziguava as inquietações e gerava esperança:

Assim, o poeta não conseguindo encontrar o lenitivo para a sua angústia face à situação que reinava no país, foi levado a pensar que só a construção ou renovação e difusão consequente e multímoda de um grande mito nacional, o mito sebastianista, poderia levantar o moral da nação. E daí nascerão as Novas Descobertas, a criação do Mundo Novo, o Quinto-Império. Terá regressado El-Rei D. Sebastião. (CAMEIRÃO, 2000, p. 21).

Enquanto associação sócio-cultural, a Renascença Portuguesa desenvolveu atividades com o propósito educativo

6 O Quinto Império é uma crença messiânica e milenarista que aparece reformulada nas profecias de Gonçalo Ennes Bandarra (1500?-1556), nos textos do padre António Vieira no século XVII, na obra de Fernando Pessoa (1888-1935) e também em Agostinho da Silva (1906-1996). O mito tem origem no texto bíblico do Antigo Testamento, no qual o profeta Daniel decifrou o sonho da estátua com pés de barro do rei da Babilônia, Nabucodonosor. O profeta afirmava que depois da magnificência do império babilônico sucederiam outros, segundo a vontade de Deus. De acordo com as interpretações mais correntes, seriam esses impérios: o Medo-Persa, o Grego, o Romano e o Quinto Império universal. Segundo o Padre Vieira, os quatro primeiros impérios eram pela ordem: o Assírio, o Persa, o Grego e o Romano e o quinto seria o Império Cristão Português. Na leitura de Fernando Pessoa, os quatro primeiros impérios diferiam dos de Vieira, sendo o primeiro o Grego, o segundo o Romano, o terceiro o Cristianismo e o quarto a Europa. "Pessoa fazia assim do seu Quinto Império, Portugal, a nação onde ele próprio teria lugar, ou, como já formulou Jacinto do Prado Coelho, quando em 1964 foram publicados os primeiros textos sobre esta questão: 'Pessoa propõe a Portugal, sua criatura, a aventura espiritual em que ele próprio se empenhou', 'o Quinto Império em que todos os Portugueses, segundo o poeta, deveriam colaborar assemelha-se estranhamente ao que ele próprio empreende pelo desdobramento nos heterónimos [...]' ". Cf. URIBE; SEPÚLVEDA, 2012, p. 153. 
e de promover a autonomia dos intelectuais republicanos em relação à esfera política. Fizeram parte desse movimento alguns importantes expoentes do mundo das letras portuguesa, tais como: Jaime Cortesão (1884-1960), Teixeira de Pascoaes (18871952), Raúl Proença (1884-1941), António Sérgio (1883-1969), Leonardo Coimbra (1883-1936), Augusto Casimiro (1889-1967), Álvaro Pinto (1889-1957), dentre outros.

O grupo visava criar um público consciente e ilustrado. Teve como principal mentor, sobretudo até 1916; Teixeira de Pascoaes, com a sua teoria do saudosismo ${ }^{7}$. Numa segunda fase, Leornardo Coimbra assumiu esse papel. Privilegiou-se o uso dos termos "regeneração", "ressurgimento" e "renascença", com vistas a insinuar que o enfermo do ocidente, apesar de tudo, devia ter esperanças de levantar-se do seu leito de moribundo e caminhar para a frente (PINHO e NATÁRIO, 2011, p. 16).

A Águia tornou-se o principal espaço de divulgação ${ }^{8}$ das ideias do movimento:

O fim d'esta revista, como órgão da 'Renascença Portuguesa' será, portanto, dar um sentido as energias intelectuais que a nossa raça possue; isto é, colocá-las em condições de se tornarem fecundas, de puderem realizar o ideal que, n'este momento histórico, abrasa

7 A doutrina saudosista não era consenso entre os representantes da Renascença. Há manifestações críticas contra tal teoria, inclusive nas páginas d'Águia, por parte de António Sérgio e de Raul Proença. Cf., por exemplo: ANTÓNIO SÉRGIO. Regeneração e tradição, moral e economia. A Águia, n. 25, p. 1-9, 1914.

8 Além de A Águia, o grupo da Renascença também editou o boletim Vida Portuguesa. O "quinzenário de inquérito à vida nacional" foi publicado entre outubro de 1912 e novembro de 1915, sob a direção de Jaime Cortesão, perfazendo 39 números com distribuição no Brasil. A partir do número 17, lia-se "Boletim de inquérito à vida nacional" e, do número 21, apresentava-se como "Boletim da Renascença Portuguesa". A publicação abordava temas de literatura, artes, ciência, filosofia e crítica social, conferindo atenção especial a divulgação do trabalho na frente educacional desenvolvido pelo movimento. Assim sendo, apresentou-se várias matérias sobre as universidades populares, o ensino infantil, dentre outras questões. 
todas as almas sinceramente portuguesas: - Crear um novo Portugal, ou melhor ressuscitar a Pátria Portuguesa, arrancá-la do tumulo de alguns seculos de escuridade fisica e moral, em que os corpos definharam e as almas amorteceram. (A ÁGUIA, n. 1, p. 1,1912$)^{9}$.

Segundo o pensamento de Teixeira de Pacoaes, a saudade era entendida como manifestação suprema do modo de ser português. O saudosismo lusitano, pautado no messianismo, surgia como a única forma de elevação e de redenção do povo. "A Saudade, 'alma da Raça', é a força criadora e redentora, que, sobre a lembrança dum passado inspirado, deve criar o desejo duma redenção sobre as sombras do presente" (CAMEIRÃO, 2000, p. 23).

Nessa concepção havia uma valorização do particular, embora não fosse impedido o acesso ao universal. A Pátria e a Raça participavam do universalismo, porque estavam "intimamente ligadas à Humanidade". Segundo esses princípios, o patriotismo seria a maneira mais autêntica de se ser cosmopolita. Sendo assim, "o 'bom português' devia cultivar em si o patriota que abrange o indivíduo, o pai e o munícipe e os excede" (PINHO; NATÁRIO, 2011, p. 16).

Defendia-se, portanto, uma República Portuguesa dedicada a atender às demandas sócio-culturais do país, ultrapassandose a tendência de se reproduzir um modelo político afrancesado. Por povo português entendia-se, sobretudo, as comunidades rurais, devido à sacralização do seu trabalho em comunhão com a natureza (PINHO; NATÁRIO, 2011, p. 16).

A interiorização desses valores exigia o corte com a educação clerical e com o enquadramento ultramontano do religioso. Somado a isso, fazia-se necessária uma reforma educativa que abarcasse "as necessidades de sacralidade inerentes aos costumes, bem como as inquietações do ser humano perante os enigmas do mundo e da vida" (PINHO; NATÁRIO, 2011, p. 16).

9 Optamos por manter a grafia orginal em todas as transcrições de documentos. 
Somente dessa forma, poderiam ser os valores verdadeiramente renascentes.

O movimento da renascença não aceitava, no entanto, o radicalismo agnóstico no tratamento da questão religiosa. Buscava-se "refundar uma vivência da sacralidade mediada, não por Roma, mas por uma Igreja lusitana 'que tão vivas raízes tem na tradição e no espírito da Raça' " (PINHO; NATÁRIO, 2011, p. 16).

A Águia teve um papel importante no intercâmbio cultural Brasil-Portugal, pois manteve entre seus colaboradores escritores brasileiros ${ }^{10}$ e contou com uma significativa distribuição no Brasil. Além disso, houve um período em que a revista foi editada no Rio de Janeiro (1920-1921) pelo jornalista português Álvaro Pinto ${ }^{11}$.

Para nós, torna-se interessante acompanhar, sobretudo, a segunda série de A Águia (1912-1921), conferindo especial atenção aos dois anos em que a mesma foi impressa no Rio. Esse período mostrou-se relevante, pois os escritores reunidos em torno da Renascença Portuguesa criaram a Sociedade LusoBrasiliana e, assim, fundaram a editora Anuário do Brasil.

No seu estudo sobre a trajetória do intelectual-imigrante Álvaro Pinto no Brasil, Raquel Souza (2012, p. 3-4) confere destaque ao papel desempenhado por esse jornalista na articulação de um projeto cultural que privilegiava o intercâmbio luso-brasileiro. O projeto apareceu materializado nas páginas

10 Conferir, por exemplo: COELHO NETO. A Partida (n. 3, p. 3-4, jan. 1911); COELHO NETO. Atracção da Terra (n. 4, 2a série, p. 118-121, abr. 1912); MATEUS DE ALBUQUERQUE. Eça de Queiroz (n. 7, 2 a série, p. 32-36, jul. 1912); COSTA MACEDO. Os Covas (n. 8, $2^{\mathrm{a}}$ série, p. 65-70, ago. 1912); MÁRIO DE ALENCAR, Carta a Carlos Magalhães de Azeredo (ns. 106/107/108, p. 100-124, out.-dez. 1920); ROCHA POMBO, A Reacção contra os Intrusos (ns. 109/110/111, p. 37-51, jan.-mar. 1921).

11 Álvaro Pinto (1889-1956) foi diretor, secretário e administrador de algumas das mais prestigiadas publicações de Portugal, na primeira metade do século XX. Além dos cargos (secretário, diretor, correspondente) ocupados n'A Águia (1910-1925), foi também diretor da revista Ocidente (entre 1937 e 1956). Dirigiu, ainda, a revista Terra de Sol (1924 a 1925), editada no Rio de Janeiro, ao lado do poeta brasileiro Tasso da Silveira, além de outras revistas de mais curta duração. 
d' A Águia, quando a mesma foi editada no Rio, por meio da seção intitulada "Carta do Brasil". Nesse espaço do periódico foram discutidos diversos assuntos como, por exemplo: as questões do imigrante português no Brasil, as comemorações do Centenário da Independência brasileira, a campanha nativista e temáticas socioeconômicas brasileiras do período, dentre outros.

Na primeira carta, de abril de 1920, Álvaro Pinto, então um dos diretores d' $A$ Águia ${ }^{12}$, referia ao quão bem recebida havia sido a revista e a Renascença Portuguesa no Brasil. Era, pois, dever dar a conhecer Portugal ao público brasileiro com estudo aprofundado acerca da literatura, do desenvolvimento comercial, industrial e dos costumes portugueses.

O tema do imigrante luso no Brasil ocupou considerável espaço nesse artigo. $O$ autor afirmava que o país necessitava de grande movimento imigratório. Aos portugueses caberia "apresentarem-se com pleno conhecimento dos seus fins", munidos de instrução acerca do trabalho, respeito, tolerância e ordem para com a nova sociedade. Essa deveria ser a premissa para os imigrantes "que buscam em terra alheia o emprego de atividades que não podem encontrar na sua” (A ÁGUIA, ns. 101/102, p. 188, 1920).

Segundo o publicista, fazia-se necessário a criação de uma escola que orientasse todos aqueles que desejassem emigrar. Era imperativo organizar o encaminhamento dos imigrantes portugueses para as áreas e atividades do território brasileiro em que fossem realmente precisos. Dessa forma, evitar-se-iam a sobrecarga dos serviços no comércio das cidades litorâneas e as críticas dos movimentos nacionalistas em torno desse perfil da comunidade lusa (A ÁGUIA, ns. 101/102, p. 189, 1920).

12 Nessa altura, era também diretor d' A Águia o pintor, professor e poeta António Carneiro (1872-1930). Desde a edição dos números 91/92/93 de 1919, o nome do pintor e de Álvaro Pinto constavam na direção do periódico. No entanto, Carneiro ocupava esse cargo desde 1912, ao lado de Teixeira Pascoaes, mantendo-se no mesmo até os números 118/119/120 de 1921 . 
Essa característica da imigração portuguesa foi tema da conferência de Malheiro Dias ("Rumo à Terra13"), realizada em 1917, retomada em matéria de A Águia, por ser considerado pertinente divulgar as ideias defendidas na mesma. Segundo essa conferência, a finalidade principal da colônia lusa no Brasil era ajudar a manter a unidade espiritual brasileira, evitando a tendência à desagregação causada pela imigração de outras nacionalidades. Percebe-se, nesse ponto, uma aproximação à ideia de Sílvio Romero acerca do elemento português no Brasil (1902), quando o escritor identificava o imigrante luso como responsável pela manutenção da feição histórico-cultural do país.

No entanto, a colônia portuguesa pela inclinação a fixarse no comércio do litoral, enquanto os outros imigrantes dirigiam-se ao trabalho agrícola no interior, afastava-se do seu propósito integrador. Tal conduta causava ainda empecilhos ao desenvolvimento da própria colônia. Nesse quadro, as áreas colonizadas por imigrantes alemães e italianos impunham-se também nas atividades comerciais, gerando concorrência ao comércio português. Tendo em vista essas questões, defendia Malheiro Dias:

O que é preciso, o que é indispensável é desviar da fascinação urbana os lavradores, que muito melhor poderão colaborar na grandeza do Brasil, na prosperidade de Portugal e na hegemonia da nossa raça comum, estabelecendo-se na terra, cultivando a terra. (A ÁGUIA, ns. 103/104/105, p. 36, 1920).

Na visão de Álvaro Pinto, os cuidados ao emigrante que deixava Portugal deveriam ser pensados no contexto de um verdadeiro intercâmbio com o Brasil. Não se tratava de uma mera aproximação, mas de "um intenso estreitamento da amizade e contratos, em que Portugal reconhecendo o incalculável auxilio que o Brasil póde dispensar-lhe, se esforce por corresponder a

13 Tema referido por Malheiro Dias em entrevista concedida à revista Atlântida (n. 19, p. 603, 1917). 
ele trabalhando com igual ardor no engrandecimento do povo irmão". (A ÁGUIA, ns. 101/102, p. 189, 1920).

O jornalista afirmava, ainda, que não era com "missões de amadores, viagens de três meses, conferencias políticas, bailes e banquetes", as bases em que se dariam o intercâmbio proposto. Para isso, fazia-se necessário um programa acordado entre as Embaixadas e os Ministérios dos Negócios Estrangeiros de cada país, estabelecendo-se um tratamento oficial para o estreitamento das relações (A ÁGUIA, ns. 101/102, p. 189, 1920).

É bem provável que o objeto das críticas de Álvaro Pinto tenha sido o escritor português João de Barros ${ }^{14}$, que se encontrava na sua segunda viagem ao Brasil, entre abril e junho de 1920, realizando conferências em prol de uma aproximação lusobrasileira. Numa outra carta, o diretor de A Águia remeteu-se ao poeta como "vistosa borboleta das letras portuguesas", revelando tensão entre os círculos literários lusos da época:

Você [João de Barros] sonhou destruir a Águia com a Atlântida. Falhou. Você sonhou destruir as edições da 'Renascença' com as suas. Falhou. Você sonhou reduzir Portugal-Brasil a duas simples pessoas. Falhou. Eu não posso ser seu inimigo, porque absolutamente nada, até hoje, V. tem colhido no meu campo ou eu tentado colher no seu. Cortei em determinado tempo relações consigo, porque o vi demasiado senhor do seu lugar burocrático, tratando-me do alto. Mas, não tive duvida alguma em as reatar, quando V. o desejou. Não faço versos [...]. Sou portanto insuspeito para falar de si. E por isso me atrevo a não concordar com a sua fórmula tão estreita de intercâmbio, que conduz a fazer de V. a expressão máxima da Raça. (AÁGUIA, ns. 112/113/114, p. 115, 1921).

14 O poeta foi também alvo de crítica em matéria do boletim $A$ Vida Portuguesa, conforme referido, periódico da Renascença Portuguesa. No artigo em questão, João de Barros foi repreendido pelo texto que remetera a um jornal brasileiro, no qual afirmava não haver nada que fosse digno de nota nas letras portuguesas da época corrente, pois os intelectuais encontravam-se absorvidos pela política. Essa afirmação foi contestada, tendo em vista a significativa produção literária da Renascença Portuguesa. Conferir: O snr. João de Barros. A Vida Portuguesa, n 19, p. 148-149, 1 nov. 1913. 
Podemos inferir, que as querelas entre os grupos literários portugueses estendiam-se ao tratamento conferido à questão das relações luso-brasileiras. A fundação da Atlântida é percebida como concorrência. Por meio dessa espécie de desabafo, percebe-se que o publicista questionava a forma como Barros vinha fazendo a campanha de aproximação entre os dois países. Segundo essa visão, Barros teria monopolizado a causa, reduzindo-a a uma parceria com o cronista carioca João do Rio, em tom de "conversas de café e aventuras galantes" (A ÁGUIA, ns. $112 / 113 / 114$, p. 116,1921$)$.

Algo que deixou o jornalista indignado foi o comentário feito por João de Barros, quando o mesmo esteve no Brasil, dizendo-se ser o único português que não buscava tirar proveito financeiro do país. Esta declaração não foi bem recebida, tendo em vista o percurso de Álvaro Pinto que emigrara para o Rio de Janeiro, assim como outros intelectuais portugueses, com o propósito de fundar a editora Sociedade luso-brasiliana e dedicar-se a esse projeto em parceria com o escritor António Sérgio. O então diretor d'A Águia chegou a insinuar que o recrudescimento do nativismo brasileiro, com o caso dos poveiros ${ }^{15} \mathrm{e} o$ avanço da linguagem

15 Nesse período, a pesca no Brasil era predominantemente exercida por portugueses originários de Póvoa de Varzim ("os poveiros"), sobretudo no Rio de Janeiro e no Pará. Em Santa Catarina, por portugueses açorianos e no litoral de São Paulo e de Cabo Frio por pescadores japoneses. Para regularizar o processo foi elaborada uma circular em 5 de agosto de 1920, que estabelecia o prazo de 90 dias para os pescadores estrangeiros naturalizarem-se, sendo que para São Paulo, Rio de Janeiro e Espírito Santo foram concedidos 60 dias. Esse fato alimentou os ressentimentos entre portugueses e brasileiros, produzindo visões críticas quanto à defesa de um estreitamento das relações luso-brasileiras. À medida que o capitão Villar fez vigorar a circular e começou a negar a matrícula de pesca aos portugueses houve uma mobilização por parte da comunidade lusa em campanha a favor dos poveiros, com grande repercussão na imprensa carioca. O caso, levado a tribunal por alguns pescadores portugueses, gerou imensas polêmicas e polarizou a questão. De um lado encontrava-se a comunidade lusa, comandada pelo Embaixador Duarte Leite, que se colocava contra as naturalizações e do outro, favorável ao cumprimento da lei; o Governo brasileiro, as organizações do nacionalismo nativista e seus apoiadores. Dentre os episódios extremos que marcaram a 
xenofobista, poderia ter sido, de alguma forma, influenciado pela passagem de Barros pelo Brasil (A ÁGUIA, ns. 112/113/114, p. 116, 1921).

Sobre a campanha nativista, Pinto questionava o fato do elemento luso ser alvo da mesma, visto que era dos imigrantes mais assimiláveis, devido às proximidades culturais entre portugueses e brasileiros:

Os ataques dos nativistas aos lusos não passam a maior das vezes de paradoxais arrufos de familia entre o Português já assimilado e o Português em via de assimilação [...]. Ao pai português sucede o filho brasileiro, a empresa que começa portuguesa na mão do primeiro continua brasileira na mão do segundo. (A ÁGUIA, ns. 101/102, p. 190, 1920).

Nessa mesma carta afirmava ainda, que os maiores detentores e exploradores das riquezas econômicas brasileiras eram de agrupamentos ingleses, alemães, franceses e italianos. No entanto, a imprensa nacionalista radical denunciava, sobretudo, o monopólio econômico português nos principais centros urbanos brasileiros da época (A ÁGUIA, ns. 101/102, p. 191, 1920).

Em outro artigo assinado pelo publicista, o tema do nativismo foi retomado. Álvaro Pinto, considerava que essa questão deveria ser tratada com serenidade e estudo calmo. Relativizava o tema, dizendo ter havido em várias épocas conflitos entre brasileiros e portugueses no Norte do Brasil. Entretanto, tais embates localizados teriam sido exagerados pela imprensa portuguesa (A ÁGUIA, ns. 112/113/114, p. 120, 1921).

Colocava-se, ainda, como exemplo de emigrante português que tinha sido bem recebido no Rio de Janeiro, onde se dedicava à atividade editorial. $\mathrm{O}$ autor frisava que os ataques

intensa batalha na questão dos poveiros, deu-se a agressão do capitão Villar à João do Rio, este último defensor aguerrido dos pescadores portugueses. Contudo, os poveiros acabaram por deixar o país sob o lema: "Antes sem pão do que sem pátria”. Conferir: SABINA RIBEIRO, Gladys, 2001, p. 147-162. 
mais contundentes aos portugueses se resumiam, sobretudo, a um panfleto carioca (provavelmente, a Gil Blas ${ }^{16}$ ), o qual não representava o pensamento do Brasil (A ÁGUIA, ns. $112 / 113 / 114$, p. 120-121, 1921). No tocante a essa discussão, o posicionamento de Álvaro Pinto apresenta-se próximo ao de João de Barros. Nos seus escritos, o poeta também analisava o nativismo como algo pouco representativo da visão da sociedade brasileira do período em relação ao português e à cultura lusa.

É difícil mensurar a relevância do intercâmbio cultural fomentado pela AÁguia, mas certamente teve o seu contributo ao atualizar os debates presentes em ambas as sociedades, seja no campo literário ou político. Arnaldo Saraiva analisa positivamente o papel da revista nesse contexto, sobretudo, no aspecto da aproximação humana e cultural entre portugueses e brasileiros, em tempos particularmente difíceis:

Nenhuma outra instituição, nem nenhum governo, desenvolveu em tal domínio uma ação que se lhe possa comparar. Porque os intelectuais que idealizaram A Águia e a Renascença Portuguesa não se limitaram a atuações episódicas, não se contentaram com almoços, discursos, reuniões, acordos sem consequência, nem se ficaram pela revista. Eles deram-se conta muito cedo do que em nossos dias se tarda em descobrir: que não pode manter-se viva a cultura portuguesa no Brasil ou a brasileira em Portugal sem a edição de livros portugueses no Brasil e brasileiros em Portugal (2004, p. 91-92).

16 Revista publicada no Rio de Janeiro, nos anos de 1919 a 1923. Fundada e dirigida pelo jornalista, político e ensaísta brasileiro Alcebíades Delamare (1888-1951). O semanário propunha um nacionalismo radical defendido na maior parte de seus artigos. Muitas matérias enveredavam por um discurso de exacerbado nacionalismo antilusitano. Cf.: JESUS (2012). 


\section{Nação Portuguesa: o hispanismo e o Brasil}

Publicou-se na Nação Portuguesa ${ }^{17}$, revista do Integralismo Lusitano, em número dedicado a prestar homenagem ao Brasil: "Saudemos no Brasil o adolescente heroico nosso herdeiro, continuador da raça e língua nossas, mantenedor da Lusitanidade e do seu ritmo imortal" (n. 11, p. 489, 1923). Destacou-se, portanto, nessa matéria a ideia do Brasil como perpetuador da cultura portuguesa na América.

A revista foi criada pouco antes da deflagração da I Guerra Mundial por um grupo de jovens monárquicos, reunidos na Universidade de Coimbra. Circulou de forma seriada entre 1914 e 1938 sem periodicidade definida, com interrupção da publicação no período de 1917 a $1921^{18}$. Tornou-se, portanto, a principal porta-voz ${ }^{19}$ do chamado Integralismo Lusitano, movimento que com a implantação da República em 1910, transitou da simples tertúlia literária à ação política.

Fizeram parte desse movimento nacionalista e tradicionalista, por opção estético-filosófica, nomes como: António Sardinha (1887-1925), Alfredo Pimenta (1882-1950), José Hipólito Raposo (1885-1953), Alberto de Monsaraz (1889-1959), Luiz de Almeida Braga (1886-1970), José Adriano Pequito Rebelo (1892-1983), Rolão Preto (1893-1977), dentre outros ${ }^{20}$. Este último, um dos

17 Disponível para consulta no acervo da Biblioteca Museu República e Resistência. Rua Alberto de Sousa, n 10 A - Zona B do Rêgo, 1600-002, Lisboa - Portugal; [http://republicaresistencia.cm-lisboa.pt/] .

18 Nesse período publicou-se o diário integralista da tarde, A Monarquia, 12 de fevereiro de 1917, com Alberto de Monsaraz na direção e redator-chefe, João do Amaral.

19 Entretanto, não foi cronologicamente a primeira publicação coletiva do movimento integralista. Antes da Nação Portuguesa, editou-se no exílio, na cidade de Gand (Bélgica), a Alma Portuguesa. Foram então publicados dois números, em maio e setembro de 1913, cujo subtítulo era Órgão do Integralismo Lusitano. Cf.: CARVALHO, Paulo Archer, 1993, p. 3.

${ }^{20}$ Cecília Barreira (1982, p. 1422) em seu estudo sobre o Integralismo Lusitano elenca uma segunda geração integralista: Afonso Lucas (1893-1946), Manuel 
integrantes mais novos dessa primeira geração integralista, estabeleceu os vínculos entre o movimento e os ideais fascistas e primo-riveristas da época.

Eram personagens reconhecidos na comunidade estudantil de Coimbra pelo elitismo e acentuado aristocratismo intelectual. Tinham origem em grande parte na pequena aristocracia ou no latifúndio alentejano, no entanto, nem todos provinham de famílias abastadas. A maior referência ideológica externa do grupo foi o movimento monarquista e nacionalista francês, criado no final do século XIX: a Action Française ${ }^{21}$ (COSTA PINTO, 1994, p. 26).

A produção intelectual da corrente integralista dedicou-se a estudos históricos sobre a identidade nacional portuguesa. Reinventaram a tradição de uma sociedade orgânica e corporativa, da qual o Portugal medieval teria sido paradigma e que o liberalismo do século XIX, enquanto produto da importação, acabou por destruir. Segundo essa interpretação, entendia-se o período medieval como a fase de maior perfeição da sociedade portuguesa (COSTA PINTO, 1994, p. 25).

Os integralistas defendiam uma nação organizada e hierarquizada segundo a tradição, em oposição à soberania popular. A forma de representação deveria pautar-se no corporativismo dos núcleos tradicionais (a família, os municípios e as profissões) em oposição ao sufrágio universal. Uma Assembleia Nacional representativa dos segmentos sociais, com um caráter consultivo e técnico, deveria substituir o parlamento. Contrapunham, ainda, à centralização do Estado liberal, considerada responsável pela destruição da vida local e pela urbanização descontrolada, uma

Múrias (1900-1960), Pedro Teotónio Pereira (1902-1972), António Rodrigues Cavaleiro (1902-?), Marcelo Caetano (1906-1980).

${ }^{21}$ A revista nacionalista, anti-semita e germanófoba Action Française foi fundada por Charles Maurras (1868-1952) em Paris, no ano de 1908. Principal órgão do Nacionalismo Integral, fundamentado na defesa da monarquia tradicional, hereditária, antiparlamentar e descentralizada. As principais ideias da filosofia de Maurras respaldavam-se num intenso nacionalismo, na crença numa sociedade ordenada e elitista e na defesa da Igreja Católica Apostólica Romana. Cf., por exemplo, WEYEMBERGH (1992). 
descentralização do poder anti-cosmopolita e um processo de ruralização da sociedade (COSTA PINTO, 1994, p. 29).

No editorial programático, intitulado "O que nós queremos", apresentado em número inaugural da Nação Portuguesa, essas questões aparecem pormenorizadas. Destacamos alguns pontos do pensamento do grupo:

Monarquia orgânica tradicionalista anti-parlamentar - A) Tendencia concentradora (Nacionalismo) - Poder pessoal do Rei Chefe de Estado; 1. Função governativa suprema: por ministros livremente escolhidos, especializados tecnicamente, responsáveis perante o Rei [...] 2. Função coordenadora, fiscalisadora e supletoria das autarchias, locaes, regionaes, profissionaes e espirituaes [...] 3. Funções executivas, fazendo parte da função governativa suprema [...]; defesa diplomática.

B) Tendencia Descentralisadora - 1) Aspecto Economico Corporação: sindicatos operários, patronaes e mixtos, sua personalidade juridica, fiscalisação da empreza, fomento dos interesses comuns, arbitragem, etc. [...] - Nação economica: Politica economica do governo central (Rei, ministros, conselhos técnicos, função supletoria de fomento, protecionismo, tratados de comercio) função de fiscalização e coordenação dos varios graus da hierarquia economica. 2) Aspecto familiar administrativo: - Família: Unidade (patrio poder); Continuidade (indissolubilidade conjugal; vinculação luta contra o absenteísmo; vinculação propriamente dita: morgadio, homestead). - Paroquia: representação de um conjunto de famílias pelos seus chefes. - Municipio: representação de um conjunto mais amplo de famílias pelos seus chefes e de quaesquer outros organismos sociaes de importancia [...] 4) Aspecto espiritual: - Intrução primaria no municipio. - Instrução secundaria na provincia. - Universidade Autonoma (Coimbra) [...] Religião: Liberdade e privilegios da religião tradicional Catholica, Apostolica, Romana. Proteção a esta religião e prestação de auxilio material em regimen concordatario. - liberdade de congregação. - liberdade de ensino. (NAÇÃO PORTUGUESA, n. 1, p. 4-6, 1914). 
Por meio desse programa, podemos depreender que os princípios do Integralismo Lusitano divergiam das ideias defendidas pelo grupo portuense republicano da Renascença Portuguesa. A começar pela defesa do regime monárquico, a visão sobre o catolicismo e todo um ideário de sociedade inspirado num Portugal feudal, que se projetava num plano de regeneração do país.

Enquanto o grupo da renascença via na instauração do regime republicano novas possibilidades de regeneração de Portugal e, para isso, preconizavam o rompimento dos laços com a Igreja Católica, os integralistas opunham-se a essas concepções. Para os últimos, a República implantada representava uma nova etapa de decadência do país. Nesse sentido, os integralistas buscavam a regeneração por meio do retorno à integralidade do espírito católico que fizera Portugal. Havia, ainda, uma defesa comum às duas correntes em torno da importância da ruralidade, no entanto, apoiada em pressupostos teóricos diferentes.

A primeira série da Nação Portuguesa (1914-1916) apresentava o subtítulo "Revista de Filosofia Política", sob a direção de Alberto Monsaraz. Dessa fase inicial, emergiram alguns dos nomes já citados e com maior destaque na geração integralista. A partir da segunda série (1922-1924) $)^{22}$, foi dirigida

22 Publicou-se ainda: III Série, cujo subtítulo permanecia "Revista de Cultura Nacionalista" (1924-1926); sob a direção de António Sardinha, apenas nos dois primeiros números, devido a sua morte a 10 de janeiro de 1925. Após o ocorrido, assumiu a direção do periódico Manuel Múrias e Rodrigues Cavalheiro. Na IV Série (1926-1928) manteve-se o mesmo subtítulo e o diretor foi Manuel Múrias. Ocupou o posto de Secretário Marcelo Caetano, desde novembro de 1927. Na V (julho de 1928 a junho de 1929) e VI (1929-1931) séries conservou-se sob a mesma direção e secretariado. Depois de 1931, a revista passou a ser publicada em volumes. Ao longo desse período, permaneceu sob a direção de Manuel Múrias e teve Fernando Campos como secretário. Volume VII (doze números, 1932-1933). Volume VIII, quatro fascículos de 1933 a 1934. Volume IX, seis fascículos, 1934. Volume X, seis fascículos de 1936 a 1937. Volume XI, seis fascículos de 1937 a 1938. Segundo Barreira, Manuel Múrias imprimiu à Nação Portuguesa uma orientação (de 1925 a 1938) que, paulatinamente, se distanciou do Integralismo e foi assumindo um perfil de obediência e passividade requeridas à mentalidade do regime salazarista (1982, p. 1424). 
por António Sardinha e juntaram-se outros nomes ao corpo editorial, tais como: Afonso Lopes Vieira (1878-1946), Castelo Branco Chaves (1900-1992), Vieira de Almeida (1888-1962) e Avelino Soares. Passou a apresentar o subtítulo; "Revista de Cultura Nacionalista". O nosso interesse concentra-se nesses dois momentos da revista.

Os responsáveis pelo periódico abordaram, sobretudo, temas voltados à economia e à política. Conforme vimos, defendiam a monarquia tradicional, não absolutista e antiparlamentar, bem como os privilégios e papel da religião católica na sociedade portuguesa. Fomentaram uma herança nacionalista militante, com o objetivo de promover o ressurgimento nacional. A defesa de um conjunto de ideias nacionalistas, com vistas a um renascimento do país também era intuito da Renascença Portuguesa, reunida em torno da revista A Águia, referida anteriormente.

Segundo Barreira, a colaboração do poeta, historiador e político António Sardinha na Nação Portuguesa foi marcante, tornando-se um dos integralistas mais celebrizados. Escreveu grande parte dos editoriais e também foi responsável pelos principais textos de doutrinação política do periódico. Podemos destacar três temas, aos quais o escritor dedicou-se mais rigorosamente: o hispanismo, o municipalismo e a recuperação dos teóricos (Herculano, Garret e Teófilo Braga) da contrarevolução (1982, p. 1423).

Interessa-nos aqui aprofundar o conceito de hispanismo, por ser bastante significativo para entendermos como essa corrente pensava a formação histórico-cultural de Portugal e o papel do Brasil nesse conjunto de referências. A tese da hispanidade, defendida pelos integralistas e sobretudo nos artigos de Sardinha, opunha-se ao modelo de latinidade propagado por parte da intelectualidade francesa desse período. Segundo a visão hispanista, a Península Ibérica era considerada a essência da civilização cristã ocidental. Um ponto importante nesse debate, é que os integralistas propugnavam apenas a unidade espiritual e não política entre Portugal e Espanha. 
Num artigo intitulado "O genio peninsular", Sardinha inicia o texto referindo-se ao Doze de Outubro, data da chegada de Colombo à América, quando é celebrada a Fiesta de La Raza em Espanha. Definiu raça no sentido de civilização e afinidade moral, não se tratando somente do aspecto étnico. Afirmava que na literatura do século XVI, até mesmo em Camões, o termo "hespanhoes" era utilizado para se referir às gentes que habitavam a Península Ibérica, incluindo-se os portugueses:

Dentro deste quadro, a unidade hispânica se comprendia como uma especie de super-nacionalismo, tão intimamente cimentado na consciencia da gloriosa época de Quinhentos que Camões, cantando a plenitude da afirmação portuguêsa, a incluia sem desdoiro nem subalternização no molde físico e cultural que a Península representava perante o mundo curvado ao prestigio das suas irradiações. (NAÇÃO PORTUGUESA, n. 4, p. 150-151, 1922).

Tratava-se, portanto, de se recuperar um sentimento espiritual de pertença ao denominador comum; a "madre Hispania". Essa unidade remetia ao período dos descobrimentos quando "cavaleiros da humana energia, espanhois e portugueses ampliaram os roteiros da civilização [e] afirmaram pereduravelmente um tipo inconfundível, - o tipo "hispânico» em que Camões [...] nos inseria sem desdoiro, ao chamar-nos «huma gente fortissima da Espanha»" (NAÇÃO PORTUGUESA, n. 4, p. 150-151, 1922).

De acordo com Barreira, a Hispânia de Sardinha inscreveu-se como uma utopia atemporal, no entanto, apareceu num momento político específico, isto é, no Governo de Primo Rivera (19231930). Iniciava-se uma experiência de ditadura nacionalista na Espanha, a qual poderia influenciar a Península. Breves foram as notas, antes de 1922, em que o autor se tenha dedicado a tecer comentários sobre uma política ibérica (1982, p. 1428).

O Brasil surge nos textos da revista, sobretudo, naqueles escritos por António Sardinha, quando o autor trata do conceito de Hispanismo. Nesse caso, ao conceito estendido às Américas somava-se o prefixo Pan, reforçando-se assim a ideia de um 
movimento para além da península ibérica. O Pan-hispanismo é entendido como a união entre Portugal, Espanha e os países "irmãos" da América, como forma de combater a doutrina que pregava a solidariedade política e econômica entre os países americanos: o Pan-Americanismo ${ }^{23}$ (MULLER, 2011, p. 184-185).

No artigo "A Lição do Brasil", dedicado ao escritor nacionalista brasileiro Jackson de Figueiredo ${ }^{24}$, Sardinha discorreu sobre o papel do Brasil no Hispanismo. Primeiramente, referiu-se ao país como a grande obra lusa, materializando os mais altos serviços prestados por Portugal à civilização: "Se outro título de glória não possuíssemos, o de descobridores e fundadores do Brasil chegaria suficientemente para nos conceder as grandezas da imortalidade!" (NAÇÃO PORTUGUESA, n. 11, p. 547, 1923).

Na sequência, dentre as considerações sobre o sentimento nacionalista em Portugal, afirmava que o Brasil se associava à sorte do país luso quer pelo passado comum, como pela função que Deus lhe reservava num amanhã resplandecente configurando-se a aproximação fundamentada na Hispanidade:

Ao lado da espontânea aproximação que apertará cada vez mais Portugal ao Brasil, formando os dois países um bloco indestrutivel- o

${ }^{23}$ Visava-se, por meio do pan-americanismo, preservar a integridade do continente americano contra outros continentes, sobretudo, o europeu. A origem desses princípios remonta ao processo de independência das nações americanas das antigas metrópoles europeias. Tal pensamento acentuou-se com a Doutrina Monroe (1817-1825), quando o então presidente dos E.U.A prescrevia a autonomia dos países americanos, simbolizada pela frase "América para os Americanos". A corrente fortaleceu-se no final de 1889, quando foi convocada a Primeira Conferência Pan-Americana pelo governo estadunidense. Cf., por exemplo: LOGUERCIO, Edgardo Alfredo (2007); BETHEL, Leslie (Org.), 2001.

${ }^{24} \mathrm{O}$ escritor sergipano Jackson de Figueiredo (1891-1928) colaborou inicialmente com o movimento nacionalista mais radical fundador da revista Braziléa (1917-1918), aproximando-se posteriormente do catolicismo. Foi um dos organizadores do movimento católico leigo no Brasil. Fundou, em 1922, o Centro Dom Vital e a revista A Ordem (1921-), por meio dos quais combateu o comunismo, o liberalismo e a revolução de modo geral. 
bloco do lusitanismo, o conceito envolvente do hispanismo revelase-nos como forçosa conclusão, abrangendo consigo, além de Espanha, nossa irmã, vinte nacionalidades que ela intrepedamente semeou por entre perigos e arrojos através da selva americana. (NAÇÃO PORTUGUESA, n. 11, p. 547, 1923).

Segundo Muller, a partir dessas considerações, Portugal arvora-se numa posição de superioridade em relação ao Brasil. Transfigura-se no "pai amoroso" que abriria ao filho primogênito as portas da "Hispânia", constituindo-se como o elo fundamental dessas relações. Seria pela herança cultural lusa que o Brasil teria o seu espaço nesse grande projeto transnacional, o qual visava, especialmente, fortalecer o homem e a raça ibérica (2011, p. 188).

Sardinha, no mesmo artigo, aprofunda a imagem do Brasil como continuador do gênio português no mundo americano. Para isso, recorreu às obras do escritor brasileiro Elysio de Carvalho ${ }^{25}$. Nessa perspectiva, o brasileiro seria fruto da civilização mediterrânea, que se estabeleceu e desenvolveu naquela parte da América. De acordo com Carvalho, não podia ser o índio o tipo nacional e o legítimo brasileiro, conforme alimentava a corrente romântica. Por brasileiro não se entendia o homem físico, mas o indivíduo moral que se formou histórico e socialmente: "Brasileiro não pode ser nem o índio, nem o africano, nem o europeu. Só pode ser o Brasileiro, isto é, o tipo que saiu da fusão dessas raças", fruto, portanto, da civilização mediterrânea (NAÇÃO PORTUGUESA, n. 11 , p. 549, 1923).

25 Elysio de Carvalho (1880-1925) foi um escritor de origem alagoana, que participou ativamente do debate sobre a questão nacional na Primeira República brasileira (1889-1930). Carvalho, assim como outros intelectuais deste período, dedicaram-se a investigar as origens dos problemas nacionais e o seu diagnóstico, além de propor soluções brasileiras para o país. O pensamento do autor destacou-se pelas características lusófila, iberoamericanista e autoritária. Dentre as principais obras, podemos citar: Brava Gente (1921), Os Bastiões da Nacionalidade (1922), Laureis Insignes (1924) e Suave Austero (1925). Cf. LEMOS, Clarici Caldini (2010). 
Ainda de acordo com o integralista, manifestava-se contra o pensamento lusófobo nativista brasileiro, o nacionalismo de Elísio de Carvalho e de Alberto Torres ${ }^{26}$. Nesse sentido, reforçavase a ideia de que a ascendência portuguesa era uma honra para o Brasil. Portanto, a partir dessa visão que reconhecia a tradição histórica cultural portuguesa como formadora do Brasil, o nacionalismo brasileiro unia-se ao nacionalismo português. Concluía Sardinha:

Para o brasileiro nacionalista a história de Portugal é sua até, pelo menos, a essa primeira Missa do desembarque da gente lusíada na terra ainda enigmática de Santa Cruz. É sua em todos os primores da língua que falamos e que põe no nome de Camões o expoente máximo de uma civilização em que o Brasil se inclui no mesmo pé de igualdade que Portugal. Orgulha-se o nacionalismo brasileiro da sua ascendencia portuguesa. Orgulha-se a nação portuguesa da sua descendencia brasileira. (NAÇÃO PORTUGUESA, n. 11, p. 549, 1923).

É interessante observar nesse contexto, o fato de António Sardinha buscar minimizar os conflitos decorrentes da política de exploração metrópole-colônia, enfatizando que o Brasil, mesmo enquanto colônia portuguesa, recebera um tratamento diferenciado. Fora sempre uma parte transplantada de Portugal além-mar e não meramente um sítio exploratório (MULLER, 2011, p. 199).

Em "Definindo intenções", editorial do número da Nação Portuguesa dedicado ao Brasil, explicou-se que o intuito de se prestar uma homenagem ao país era também o de se promover

26 Alberto Torres (1865-1917) foi advogado, político e jornalista. Homem de ação e de pensamento, republicano e abolicionista, dedicou-se a estudar a realidade brasileira desenvolvendo uma concepção nacionalista da História. Seu pensamento, sobretudo, no que concerniu ao elogio da miscigenação influenciou um grupo de escritores, o qual mais tarde filiou-se ao integralismo brasileiro. Da sua experiência como homem público resultaram algumas importantes obras: Vers la paix (1909), Le problème mondial (1913), A organização nacional (1914), O problema nacional brasileiro (1914) e As fontes da vida no Brasil (1915). Cf.: BARIANI, Edison (2007). 
uma maior aproximação espiritual entre a "pátria do alémAtlântico" e Portugal. Tendo em vista que pertenciam a um tronco cultural comum, aspirava-se a formação de um «bloco hispanoamericano» ligado pelo Atlântico, que "como «mare nostrum», se volva num lago emmoldurado pelos descendentes de quantos outrora, partindo da Península Madre, o rasgaram ao cortejo triunfal das idades-modernas" (NAÇÃO PORTUGUESA, n. 11, p. 493,1923$)$.

No mesmo artigo, tratou-se ainda de marcar posição contra os "embaixadores intelectuais" que se auto-atribuíam uma representação pouco legítima de Portugal em terras brasileiras. Colocava-se em causa os exageros retóricos que procuravam "reduzir Portugal e Brasil, política e economicamente, a um termo único!". A esse respeito, aconselhava-se examinar com cuidado, inclusive a proposta da confederação luso-brasileira defendida com patriotismo por Bettencourt-Rodrigues.

Em conferência publicada na Nação Portuguesa, no mesmo número em homenagem ao Brasil, BettencourtRodrigues ${ }^{27}$ discorreu sobre as relações entre Portugal, Brasil e a diplomacia inglesa. Nessa exposição, o defensor da ideia de uma confederação luso-brasileira, fez considerações acerca do período histórico em que o Brasil fôra elevado à condição de Reino Unido a Portugal e Algarves, em 1815. O autor remeteu-se a essa estrutura política, criada no Governo de D. João VI, como a primeira forma de confederação entre os dois países.

27 António Maria Bettencourt Rodrigues (1854-1933), médico alienista português, doutorado por Paris, estabeleceu-se no Brasil entre os anos de 1892 a 1913, por ter sofrido perseguição política devido às suas convicções republicanas. Ao retornar a Portugal foi nomeado Embaixador em Paris, tendo sido demitido devido ao movimento político no Portugal de 15 de maio de 1915. Próximo ao Governo de Sidónio Pais, apoiou o golpe de dezembro de 1917, recuperando o seu cargo em Paris. Regressou à Portugal após a morte de Sidónio, tendo estado antes, durante curto prazo, na delegação portuguesa à Conferência de Paz de Paris. Escreveu o livro Uma Confederação Luso-Brasileira: factos, opiniões e alvitres (1923), no qual reuniu os vários argumentos esboçados por intelectuais brasileiros e portugueses em defesa de um sistema político confederativo luso-brasileiro. 
A partir dessa questão, conjecturou sobre o acirramento do desentendimento político, que culminou no processo da Independência brasileira em 1822 e sobre os interesses da Inglaterra em apoiar essa ruptura entre Brasil e Portugal:

O que é certo é que uma nação, como a Inglaterra, receava êsse poder nascente do Brasil, como receava, antes da separação o futuro poderio de um império lusitano, como o que sonhara $\mathrm{D}$. João IV ao dizer que 'se possuisse só o Brasil, com o reino de Angola, as praças de África, os Açores e Cabo Verde, e, juntos esses Estados com Portugal, não trocaria a sua condição pela de nenhum outro príncipe da Europa. (NAÇÃO PORTUGUESA, n. 11, p. 511, 1923).

Rodrigues defendia que as razões que fizeram com que a diplomacia inglesa tivesse apoiado a separação entre Portugal e Brasil naquela altura, deveriam servir de motivação para a busca de uma união entre os dois países. Dever-se-ia, no entanto, preservar a autonomia de cada país e promover uma solidariedade em todas as questões e problemas de ordem internacional e em tudo que se relacionasse à segurança e à defesa de ambos os países.

Nessa exposição, o projeto confederativo assumia um papel dentro de uma aliança hispano-americana. Rodrigues defendia uma Confederação Luso-Brasileira que não interferisse na independência material e moral dos povos confederados. Dessa forma, num primeiro momento, visava-se a formação da confederação entre Portugal e Brasil e depois uma aliança com a Espanha e as Repúblicas espanholas da América: "[...] assim acabaria por se constituir um novo e grande bloco, o bloco lusohispano-americano, ao qual não tardaria a juntar-se as outras nações latinas" (NAÇÃO PORTUGUESA, n. 11, p. 512, 1923).

A revista Atlântida, no pós-guerra, alimentou a ideia do latinismo, que expressava a hegemonia da cultura francesa, da qual Portugal, Espanha e o Brasil eram herdeiros. A Nação Portuguesa defendeu o Hispanismo e o papel do Brasil nessa aliança hispano-americana. Segundo essa visão, Espanha e 
Portugal equilibravam-se em harmonia de poderes. O latinismo, nesse último caso, estava vinculado ao catolicismo: "O catolicismo que amamentou a Europa e insuflou à América o hálito divino da existência [...]" (SARDINHA apud MULLER, 2011, p. 199-200).

\section{Considerações Finais}

As revistas A Águia, porta voz da corrente político-filosófica Renascença Portuguesa e a Nação Portuguesa, representante do Integralismo Lusitano, foram selecionadas pela sua importância enquanto veiculadoras das ideias de diferentes grupos de intelectuais no cenário português da época. Embasadas em referenciais teóricos divergentes e dedicadas a discutir os sentidos da nação, apresentaram perspectivas diferenciadas em torno da relação Portugal-Brasil, sobretudo a Nação Portuguesa.

Nas páginas da segunda série d' $A$ Águia, as impressões sobre o Brasil surgem na seção "Carta do Brasil", escritas por Álvaro Pinto. O jornalista português tratou de temas como as condições do imigrante português no Brasil, assim como, teceu considerações sobre o movimento nativista.

Na revista integralista Nação Portuguesa, a temática lusobrasileira é tratada a partir do conceito de hispanismo defendido por António Sardinha. Conforme vimos, segundo essa concepção, buscava-se recuperar um sentimento espiritual de pertencimento ao denominador comum: a "madre Hispania". Essa unidade remetia, segundo tal interpretação, ao período dos descobrimentos, quando os navegadores espanhóis e portugueses ampliaram os roteiros da civilização e criaram o tipo hispânico.

Fernanda Muller, no seu estudo sobre um conjunto de revistas portuguesas, dentre as mesmas a Atlântida e a Nação Portuguesa, teceu considerações acerca do papel dessas publicações na 'construção' do imaginário de comunidade (união, espiritualidade) luso-brasileira. Segundo a autora, essas revistas dedicaram-se à difusão e cooptação do público leitor, com a finalidade de angariar adesão que pudesse viabilizar os projetos arquitetados por essa elite intelectual, considerada manipuladora (2011, p. 280). 
$\mathrm{Na}$ interpretação de Muller, as "estratégias amistosas" divulgadas nas revistas desde finais do século XIX até, aproximadamente, 1922 sugerem que: "[...] cada iniciativa aparentemente isolada de cada periódico no fim integrava um plano e projeto maior de 'integração luso-brasileira', justificada pela ligação afetiva e cultural mas visando somente o beneficiamento e fomento econômico de Portugal" (2011, p. 280).

A autora compartilha do pressuposto de que a imprensa de modo geral e, particularmente, as revistas produzidas pela intelectualidade portuguesa constituíram-se como locais privilegiados de discussão acerca da escrita da História, da situação política, social, cultural e econômica de Portugal e das relações com outros países:

Transformados em veículos de propagação de idéias nacionalistas, dirigiam-se principalmente para o Brasil tentando cumprir o papel da imprensa, no sentido em que Pierre Bourdieu a concebe, ou seja: travando sobretudo uma luta política através da produção do conhecimento; buscando o reconhecimento pela produção e reprodução de capital simbólico que expressam notoriedade e respeitabilidade; afirmando sua autoridade e, por conseguinte, impondo ou criando condições para difundir e impor o conhecimento considerado legítimo e verdadeiro do sentido do mundo social, da sua significação atual e da direção em que vai e deve ir (MULLER, 2008, p. 3).

Respeitamos as colocações de Muller, entretanto a nossa percepção é de maior complexidade nos diálogos, ideias, imagens e mediações culturais promovidas por essas revistas. As mensagens em torno de uma união luso-brasileira divulgadas por tais periódicos, com ênfase na Águia e a Nação Portuguesa, encontravam-se impregnadas por um imaginário da época, ainda fortemente marcado pela herança cultural colonizadora. Havia ainda as tensões espoletadas pelos debates do movimento modernista, os quais reivindicavam uma maior autonomia literária e defendiam a ruptura e desvencilhamento das influências europeias. 
Ao nosso ver, há uma ideia que perpassava as imagens produzidas pelas correntes de intelectuais portugueses que fundaram esses periódicos: a reivindicação de uma filiação e reconhecimento do Brasil em relação à obra lusa. Não devemos, entretanto, ignorar que o interesse econômico fazia parte de toda a retórica da aproximação literária-cultural entre os dois países. Contudo, as elites intelectuais favoráveis à causa luso-brasileira encontravam-se imbuídas de uma noção de fortalecimento da cultura portuguesa, considerada comum e formadora da cultura brasileira num contexto de imperialismos culturais.

\section{Fontes Documentais: Revistas}

A ÁGUIA, n. 3, jan., 1911.

A ÁGUIA, n. 9, maio, 1911.

A ÁGUIA, n. 1, dez., 1912.

A ÁGUIA, n. 4, $2^{\text {a }}$ série, abr. 1912.

A ÁGUIA, n. 7, 2ª série, jul., 1912.

A ÁGUIA, n. 8, $2^{\text {a }}$ série, ago., 1912.

A ÁGUIA, n. 25, jan., 1914.

A ÁGUIA, ns. 52/53/54, abr./jun., 1916.

A ÁGUIA, ns. 101/102, maio/jun., 1920.

A ÁGUIA, ns. 103/104/105, jul., 1920.

A ÁGUIA, ns. 106/107/108, out./dez., 1920.

A ÁGUIA, ns. 109/110/111, jan./mar., 1921.

A ÁGUIA, ns. 112/113/114, abr./jun., 1921.

A VIDA PORTUGUESA, n. 19, 1 nov. 1913.

NAÇÃO PORTUGUESA, n. 1, 1914.

NAÇÃO PORTUGUESA, n. 4, 1922.

NAÇÃO PORTUGUESA, n. 11, 1923.

\section{Referências Bibliográficas}

BARIANI, Edison. O Estado demiurgo: Alberto Torres e a construção nacional. Caderno $C R H$, Salvador, v. 20, n. 49, p. 161-167, jan./abr. 2007. Disponível em: <http://www.scielo.br/scielo.php?pid=S010349792007000100013\&script=sci_arttext>. Acesso em: 3 nov. 2013. 
BARREIRA, Cecília. Três nótulas sobre o Integralismo Lusitano (evolução, descontinuidade, ideologia nas páginas da Nação Portuguesa, 1914-1926). Análise Social, Lisboa, v. XVIII (3.-4.-5.), n. 72-73-74, p. 1421-1429, 1982. Disponível em: <http://analisesocial.ics.ul.pt/docum entos/1223461323N1IBL3vp7Vz81PH1.pdf >. Acesso em: 2 dez. 2013.

BETHEL, Leslie (Org.). História da América Latina. São Paulo, EDUSP; Imprensa Oficial do Estado; Brasília: FUNAG, 2001. v. III.

CAMEIRÃO, Lurdes. Teixeira de Pascoaes e o projecto cultural da "Renascença Portuguesa". Bragança: Instituto Politécnico de Bragança, 2000.

CAMPOS, Névio de. História Intelectual e História Cultural: algumas aproximações. In: CONGRESSO BRASILEIRO DE HISTÓRIA DA EDUCAÇÃO, 8., 2015, Maringá. Matrizes Interpretativas e Internacionalização. Anais... Maringá, PR: Universidade Estadual de Maringá, 2015. Disponível em: <http://8cbhe.com.br/media/doc/ cdf89f13012eb62b5885ea73cb4a4212.pdf>. Acesso em 11 nov. 2015.

CARVALHO, Paulo Archer. Nação e nacionalismo: Mitemas do Integralismo Lusitano. 1993. 198 f. Dissertação (Mestrado em História Contemporânea de Portugal)-Faculdade de Letras, Universidade de Coimbra, Coimbra, 1993.

CORDEIRO, José Manuel. Nação Portuguesa (1914-1916). Que Integralismo Lusitano? Cultura, v. 26, 2009. Disponível em: <http://cultura. revues.org/443>. DOI: 10.4000/cultura.443. Acesso em 2 set. 2016.

COSTA PINTO, António. Os Camisas Azuis: ideologias, elites e movimentos fascistas em Portugal, 1914-1945. Lisboa: Editorial Estampa, 1994.

GOMES, Angela Maria de Castro; HANSEN, Patricia Santos (Orgs.). Intelectuais mediadores: práticas culturais e ação política. Rio de Janeiro: Civilização Brasileira, 2016. 
JESUS, Carlos Gustavo Nóbrega de. Revista Gil Blas e o nacionalismo de combate (1919-1923). São Paulo: Cultura Acadêmica, 2012.

LEMOS, Clarici Caldini. Os bastiões da cacionalidade: Nação e nacionalismo nas obras de Elysio de Carvalho. 2010. 203 f. Dissertação (Mestrado em História)-Centro de Filosofia e Ciências Humanas, Programa de Pós-Graduação em História, Universidade Federal de Santa Catarina (UFSC), Florianópolis, 2010.

LOGUERCIO, Edgardo Alfredo. Pan americanismo versus latino americanismo. Origens de um debate, na virada dos séculos XIX-XX. 2007. 214 f. Dissertação (Mestrado em História)-Programa de Integração da América Latina, Universidade de São Paulo, São Paulo, 2007.

MICELI, S. Intelectuais à brasileira. São Paulo: Companhia das Letras, 2001.

MIRANDA, Luciana L. de. "Brasil, visão do que fomos, do que somos e do que devemos ser": a causa Luso-Brasileira em João de Barros, 1912-1922. 2014. 192 f. Tese (Doutorado em História Contemporânea)Faculdade de Ciências Sociais e Humanas (FCSH), Universidade Nova de Lisboa (UNL), Lisboa, 2014. Disponível em: <http://hdl.handle. net/10362/13092> .

MIRANDA, Luciana L. de. Nacionalismos e nativismos nos anos de 1920: João de Barros e a aproximação luso-brasileira. Patrimônio e memória. São Paulo, Unesp, v. 11, n. 2, p. 21-51, jul.-dez., 2015.

MULLER, Fernanda Suely. A imagem de um Brasil ideal ou uma re-colonização às avessas: a importância da imprensa periódica luso-brasileira e as suas relações culturais no início do século $X X$. CONGRESSO INTERNACIONAL DA ABRALIC, 11., 2008, São Paulo. Tessituras, Interações, Convergências. Anais... São Paulo: USP, 2008. p. 1-9. Disponível em: <http://www.abralic.org.br/eventos/cong2008/ AnaisOnline/simposios/pdf/016/FERNANDA_MULLER.pdf> . Acesso em: 10 jan. 2016. 
MULLER, Fernanda Suely. (Re)vendo as páginas, (re)visando os laços e (des)atando os nós: as relações literárias e culturais luso-brasileiras através dos periódicos portugueses (1899-1922). 2011. 343 f. Tese (Doutorado em Literatura Portuguesa)-Programa de Pós-Graduação em Literatura Portuguesa do Departamento de Letras Clássicas Vernáculas, FFLCH/USP, São Paulo, 2011. Disponível em: <http://www.teses.usp.br/ teses/disponiveis/8/8150/tde-10082011-132047/en.php> .

OLIVEIRA, Lúcia Lippi. A questão nacional na Primeira República. São Paulo: Brasiliense; Brasília: CNPq, 1990.

PINHO, Arnaldo de; NATÁRIO, Celeste (Org.). A Águia e a Renascença Portuguesa no Contexto da República, 1910-2010. Porto: Universidade do Porto; Universidade Católica Portuguesa, 2011.

ROMERO, Sílvio. O elemento português no Brasil: Conferência. Lisboa: Tipografia da Companhia Nacional Editora, 1902.

SABINA RIBEIRO, Gladys. Antes sem pão do que sem pátria: o antiportuguesismo nos anos da década de 1920. Brasil e Portugal: 500 anos de enlaces e desenlaces. Convergência Lusíada, Rio de Janeiro, v. 2, p. 147-162, 2001.

SAMYN, Henrique Marques. Um vôo para o futuro com os olhos no passado: A Águia - uma experiência portuguesa contravanguardista? Revista de Letras, São Paulo, v. 50, n. 1, p.35-47, jan./jun. 2010.

SARAIVA, Arnaldo. Modernismo brasileiro e modernismo português: subsídios para o seu estudo e para a história das suas relações. Campinas/SP: Editora da UNICAMP, 2004.

SEVCENKO, Nicolau. Introdução: o prelúdio republicano, astúcias da ordem e ilusões do progresso. In: NOVAIS, Fernando A. (Coord.). História da vida privada no Brasil. São Paulo: Companhia das Letras, 2008. v. 3: República: da Belle Époque à Era do Rádio, p. 7-48. 
SILVA, Helenice R. A história intelectual em questão. In: LOPES, Marcos A. (Org.). Grandes nomes da história intelectual. São Paulo: Contexto, 2003. p. 15-24.

SOUZA, Raquel dos Santos M. Um intelectual imigrante: Álvaro Pinto e o projeto de intercâmbio Portugal-Brasil. In: CONGRESSO EUROPEU CEISAL DE LATINOAMERICANISTAS, 5., 2007, Bruxelas. Anais... Bruxelas: Université Libre de Bruxelles, 2007. Disponível em: <http:// www.reseau-amerique-latine.fr/ceisal-bruxelles/MS-MIG/MS-MIG-3MADALENO-SOUZA.pdf>. Acesso em: 10 out. 2012.

TEIXEIRA, Nuno Severiano. Política externa e política interna no Portugal de 1890: o Ultimatum Inglês. Análise Social, Lisboa, v. XXIII (4.), n. 98, p. 687-719, 1987. Disponível em: <http://analisesocial.ics.ul.pt/docume ntos/1223027734K4zTZ2wh1Lu94TC4.pdf> . Acesso em: 4 dez. 2013.

URIBE, Jorge; SEPÚLVEDA, Pedro. Sebastianismo e Quinto Império: o nacionalismo pessoano à luz de um novo corpus". Pessoa Plural, n. 1, primavera 2012. Disponível em: <http://www.brown.edu/Departments/ Portuguese_Brazilian_Studies/ejph/pessoaplural//ssue1/PDF/I1A03. pdf>. Acesso em: 12 nov. 2012.

VIEIRA, Carlos Eduardo. Intelligentsia e intelectuais sentidos, conceitos e possibilidades para a história intelectual. Revista Brasileira de História da Educação, Maringá, n. 16, p. 63-85, jan./abr. 2008. Disponível em: <http://rbhe.sbhe.org.br/index.php/rbhe/issue/view/11/showToc>. Acesso em: 10 jan. 2016.

WEYEMBERGH, Maurice. Charles Maurras et la Revolution Française. Paris: Librairie Philosophique J. Vrin, 1992.

Recebido em setembro de 2015. Aprovado em agosto de 2016. 